\title{
Usage and usability of one dry powder inhaler compared to other inhalers at therapy start: an open, non-interventional observational study in Poland and Germany
}

This study was fully sponsored by Orion Corporation (Orion Pharma)

\begin{abstract}
Introduction: Inhalation is the preferred route of drug administration for patients with asthma or COPD. It is generally predicted that there is a high error rate in inhaler usage, especially at the therapy start. The primary objective of this study was the validation of a questionnaire that can be used for assessing a successful inhalation technique, patient satisfaction as well as the compliance in daily practice.The secondary objective was to examine the "real-life" usage of one inhalation device in comparison with other devices at the start of the therapy. Material and methods: This open, multi centre and non-interventional study was designed to examine usage and usability of dry powder inhaler Easyhaler ${ }^{\circledR}$ (EH) (Orion Pharma, Finland) and other inhalers assessed by the physicians as well as by the patients.

Inclusion criteria for patients were a physician-diagnosis of COPD or asthma or children with asthmatic disease, therapy start with an inhalation device and no or only few experiences with inhaler usage (inhaler usage for not more than 3 months). Each physician enrolled an equal number of patients in each group.

Results: 263 adult/adolescent patients with asthma and 115 with COPD as well as 164 children with asthmatic disease were enrolled. $49.4 \%$ of the adult/adolescent patients with asthma used an $\mathrm{EH}$ and $50.6 \%$ other inhalers. In the case of COPD, $47.8 \%$ were treated with an $\mathrm{EH}$ and $52.2 \%$ used other inhalation devices. Finally, $50.6 \%$ of the children with asthmatic disease used an $\mathrm{EH}$ and $49.4 \%$ were treated with other inhalers.

Inhaler usage, patient satisfaction, compliance and patients assessments of usability were better when the patients used an EH. Inconvenient features were mainly documented for other inhalers. The analysis of Cronbachs alpha clearly showed the consistency of the received data from all patients. In addition, there was a large association between the assessment of the inhaler usage and the general assessment of the used inhaler in all patient groups.

Conclusion: The results of this study show that investigators found EH easy to teach, the patients found it easy to use and their satisfaction with the device was high in comparison to other inhalation devices. Thus EH can be matched to many patients already at the therapy start. In addition, the high consistency of the received data and large association of the assessment of the inhaler usage and the general assessment of the inhaler indicate that the used questionnaires were appropriate tools to examine usage and usability of inhaler devices in adult patients and children.
\end{abstract}

Key words: Asthma, COPD, inhalation therapy, Easyhaler ${ }^{\circledR}$, patient compliance, adherence, DPI

Pneumonol Alergol Pol 2015; 83: 365-377

\section{Introduction}

Asthma and chronic obstructive pulmonary disease (COPD) are two of the most common pulmonary diseases worldwide [1,2]. This gives rise to not only tremendous economic consequences, since COPD is predicted to be the third most common cause of death in 2020 [3]. There-

Address for correspondence: Piotr Hantulik, Orion Pharma Poland Sp z 0.0., ul Grochowska 278/31, 03-841 Warsaw, Poland, e-mail: piotr.hantulik@orionpharma.com DOI: 10.5603/PiAP.2015.0059

Received: 26.05 .2015

Copyright (C) 2015 PTChP

ISSN 0867-7077 
fore an effective treatment is very important. The long-term goals of asthma treatment are to achieve good symptom control, maintain normal activity levels, improve quality of life, and to minimize future risks of adverse outcomes, particularly exacerbations and fixed airflow limitations. Pharmacologic therapy of COPD is used to reduce symptoms, prevent disease progression and exacerbations, reduce mortality, as well as improve health status and exercise tolerance. All these goals should be reached with minimal side effects from medications. Thus, inhalation is the preferred route of drug administration for patients with asthma or COPD [1, 2], because the dose can be small compared with oral therapy, and the risk of systemic side effects is reduced. Furthermore, direct delivery to the airways also results in more rapid bronchodilation than oral treatment [4]. For the best outcome, regular daily controller treatment should be initiated as soon as possible after the diagnosis is made, as evidence suggests that early initiation of low dose inhaled corticosteroids in patients with asthma leads to greater improvement in lung function than if symptoms have been present for more than $2-4$ years [1].

There are a large number of inhalation devices available. The effectiveness of inhaled drugs can be influenced by several factors, for example age, education, duration, severity of disease, type of inhaler used, inhalation technique, and use of several inhalers [5, 6]. Daily practice unfortunately shows a poor control of symptoms for many patients due to problems with drug administration that limit effectiveness of therapy. Differences in effectiveness of inhalers have clinical implications [7]. It is generally predicted that there is an error rate of $50 \%$ to $90 \%$ in inhaler usage, especially at the therapy start [8]. Easy and reliable inhalation may improve inhaler competence and adherence to prescribed medications. Clinical evaluations have indicated that Easyhaler ${ }^{\circledast}$ (EH) comes close to an "ideal inhaler" including a consistent fine particle dose across a wide range of inspiratory flow rates, high lung desposition and patient preferences $[9,10]$. Several studies have shown a good inhaler competence and patient satisfaction with $\mathrm{EH}$ also in real-life settings [11-13]. However, usage and usability as well as patient satisfaction and adherence have not been tested with a patient population who start their therapy of asthma or COPD, because experiences with inhalation devices may have an influence on inhalation technique and effectiveness of therapy. In the long-term perspective there are surely also healthcare and economic advantages to prevent substitution of an inhalation drug together with the connected application errors by selecting the best inhalation device for every patient at the therapy start.

\section{Material and methods}

\section{Study design}

This open, multi-centre and non-interventional study was designed to validate a questionnaire and to examine usage and usability of EH (Orion Pharma, Finland) and other inhalers assessed by the physicians as well as by the patients. The questionnaire was designed and proposed by an independent advisory board including a pulmonologist, a pediatrician, a pharmacist and a respiratory nurse. The advisory board recommended the questionnaire for further evaluation. The study was carried out with resident physicians in Germany and Poland and was conducted in agreement with the regulations of the German and Polish Drug Laws and the relevant legal obligations for data processing and data protection in both countries. In addition, the study was submitted to the independent Ethics Commission International in Freiburg, Germany, and received a positive vote. The Polish Office for Medicinal Products in Warsaw, Poland was notified according to the current local regulations.

\section{Primary and secondary objectives}

The primary objective of the study was to validate a questionnaire that can be used for assessing a successful inhalation technique as well as the compliance of the patient in daily practice. This questionnaire should be suitable for all populations, from the children up to the multi morbid elderly patients and should help finding the best choice of device for every patient.

The secondary objective was to examine usage and usability of $\mathrm{EH}$ compared with other inhalers at the start of therapy with an inhalation device in asthma and COPD patients.

\section{Patients}

Inclusion criteria for patients were: adults with physician-diagnosed COPD or asthma, children with asthmatic disease, therapy started with an inhalation device and no or only few experiences with inhaler usage (inhaler naïve patients — inhaler usage for less than 3 months), ability to read and understand instructions (respectively in German or Polish language). Exclusion criteria: inhaler usage for more than 3 months, contrain- 
dications according to product characteristics, participation in other clinical studies. Selection of patients was at physician's own discretion taking into account the respective summaries of product characteristics. Physicians were advised to diagnose and treat asthma or COPD according to current guidelines $[1,2]$. All patients included to the study were inhaler naïve irrespectively of the time from the diagnose. Patients with a known intolerance to the active agents of the respective inhalers or milk proteins could not be included in the study. Each physician should enrol an equal number of EH-patients and patients with other inhalation devices. Overall, 54 German centres and 43 Polish centres enrolled 263 adult/adolescent patients with asthma (in Poland: 177 patients, in Germany: 86 patients), 115 adult patients with COPD (in Poland: 71 patients, in Germany: 44 patients) and 164 children ( $\leq 12$ years old) with asthmatic disease (in Poland: 136 children, in Germany: 28 children). 49.4\% (130) of the adult/adolescent patients with asthma used an $\mathrm{EH}$ and $50.6 \%$ other inhalers (133). In the case of COPD, $47.8 \%$ (55) were treated with an EH and $52.2 \%$ (60) used other inhalation devices. Finally, $50.6 \%$ (83) of the children with asthmatic disease used an EH and 49.4\% (81) were treated with other inhalers.

\section{Procedure}

Patients were informed of the nature of the study and gave their written consent to participate. Documentation was recorded at three consecutive time points: at the initial visit (visit 0 ), and at 2 weeks (visit 1) and 8 weeks (visit 2) thereafter. In the initial visit, physicians recorded demographic data, including date of diagnosis, disease severity, comorbidities, smoking habits, education, and used inhaler. In addition, they described their experiences with the inhaler training at therapy start. In the following two visits the physicians documented their general assessment of the inhaler handling, the patient's compliance as well as the occurrence of adverse events. Adult/adolescent patients were requested to fill out the 7-item questionnaire concerning the inhaler usage in all visits, including inhaler training, preparation of the inhaler for utilization, inhaler handling, success of inhalation, cleaning of the inhaler, daily activities with the inhaler (e.g. sports) as well as size and weight. Children received a 5-item questionnaire. They should also assess how easy it was to learn the usage of their inhalers and how easy it was to take along the inhaler everywhere as well as the inhaler handling in daily practice. In addition, they were asked of the ease of breathing in and the functionality of the inhaler even when the children did not take good care of it while playing. The parents or legal guardians of the children were asked to fill in the same questionnaire. The assessment of the items was made according to school marks (Germany: $1=$ very good to $6=$ insufficient, Poland: $1=$ insufficient to $6=$ very good). For analysis, the Polish school mark system was converted into the German system and the school marks of the 5 (children) or 7 (adult patients) items concerning the inhaler usage were summarized and divided by 5 or 7 , respectively to get the Inhaler Usage Score. In addition, the patients should assess their respective inhalers in general. This assessment was also made according to school marks. Furthermore, the patients could document inconvenient features of the inhaler (none, smell, taste, cough, hoarseness or other (could be specified by the patient)) and they were asked how often they used the inhaler per day (Table 1).

\section{Statistical analysis}

Statistical analysis was performed by using SAS for Windows (Statistical Analysis System, SAS Institute, Cary NC, USA). The biometric analysis comprised an elementary descriptive statistical evaluation of all collected criteria. Part of the qualitative criteria were the number of cases, the absolute and the relative frequency of each characteristic. The quantitative criteria were the number of cases as well as mean, maximum, minimum, median $1^{\text {st }}$ quantile, $3^{\text {rd }}$ quantile, standard error and standard deviation. User-defined texts were transferred into suitable coding schemes. Each item of the descriptive statistic was stratified by used inhaler and/or by diagnosis. In order to evaluate and verify the questionnaire the correlation between the answers concerning inhaler usage and the general assessment of the inhaler documented by the patients was analyzed (Pearson Correlation Coefficient r). The consistency of the answers in the questionnaires was evaluated by using Cronbachs alpha analysis. In order to evaluate possible significant differences in the assessment of the inhaler usage between patients with an EH and patients with other inhalers, the results documented in the patient's questionnaire were analyzed by using Student's t-tests (significance level $p=0.05$ ). For this analysis, the grades of every question related to inhaler usage were reassessed. The school mark 1 was reassessed as grade "very good" with value 1 and the school marks 2 to 6 were combined to one 
Table 1. Items of patient's questionnaires (assessment according to school marks: 1 (very good) to 6 (insufficient), Polish system was converted into German system)

\begin{tabular}{|c|c|}
\hline Children & Adult/adolescent patients \\
\hline \multicolumn{2}{|c|}{ Inhaler Usage Score } \\
\hline 1. How easy was it for you to learn the handling of your inhaler? & 1. How easy was it to learn the inhaler usage? \\
\hline 2. How easy is it for you to use your inhaler every day? & 2. How easy is it to prepare the inhaler for utilization? \\
\hline 3. How easy is breathing-in for you when you inhale? & $\begin{array}{l}\text { 3. How easy is it to handle/operate the inhaler, even in everyday } \\
\text { situations? }\end{array}$ \\
\hline 4. How easy is it for you to take along your inhaler everywhere? & 4. How easy is a successful inhalation, even in everyday situations. \\
\hline \multirow{3}{*}{$\begin{array}{l}\text { 5. Does the inhaler work well even when you did not take good care } \\
\text { of it while playing? }\end{array}$} & 5. How easy is it to keep the inhaler clean and ready-to-use? \\
\hline & 6. How easy are daily activities (e.g. sports) with the inhaler? \\
\hline & $\begin{array}{l}\text { 7. How easy is it to handle the inhaler and carry it along regarding } \\
\text { its size and weight? }\end{array}$ \\
\hline \multicolumn{2}{|c|}{ Inconvenient features/inhalation frequency } \\
\hline $\begin{array}{l}\text { None, Smell, Taste, Cough, Hoarseness } \\
\text { Other (specified by patient) }\end{array}$ & $\begin{array}{l}\text { None, Smell, Taste, Cough, Hoarseness } \\
\text { Other (specified by patient) }\end{array}$ \\
\hline How often did you inhale daily? & How often did you inhale daily? \\
\hline \multicolumn{2}{|c|}{ General assessment of the inhaler } \\
\hline How do you like your inhaler in general? & $\begin{array}{l}\text { How would you assess your inhaler in general according to school } \\
\text { marks? }\end{array}$ \\
\hline
\end{tabular}

grade "not very good" with value 2. Thereafter, a new Inhaler Usage Score was calculated with the reassessed values, the so-called combined Inhaler Usage Score.

\section{Results}

There was a total of 542 patients included in the study. Demographic data of these patients are shown in Table 2 divided by age (children $\leq 12$ years old, and adult and adolescent patients $>12$ years old). The most frequently mentioned other inhalers prescribed were Disc (children: $29.2 \%$, adult/adolescent patients: 19.2\%), metered dose inhaler (MDI, children: $4.9 \%$, adult/adolescent patients: $16.1 \%$ ) and Turbuhaler ${ }^{\circledR}$ (children: $23.2 \%$, adult/adolescent patients: $16.6 \%$ ). However the physicians were not only advised to treat asthma/COPD patients according to current guidelines but also to follow the respective product characteristics, the off-label use of the inhalers in paediatric population was not an exclusion criterion from the study.

The vast majority of the included children attended the elementary school (88.4\%) and 6.7\% the secondary school. Most of the adult/adolescent patients had higher graduations, in $43.4 \%$ of the cases an university entrance qualification was documented, only $3.2 \%$ of the adult/adolescent patients were without graduation.

\section{Physician's assessment of inhaler training, inhaler usage and patient's compliance of the included children}

For $88.0 \%$ of the included children that used an $\mathrm{EH}$ and $71.6 \%$ of the children with other inhalation devices the physician reported that it was very easy or fairly easy to teach the correct use of the respective inhaler. The correct use of the inhaler was achieved with one demonstration in $60.2 \%$ of the children with $\mathrm{EH}$ and in $50.6 \%$ of the children with other inhalers. Training was reported to be hard for one child, that did not use the EH. The respective instruction manual was widely comprehensible (EH: $96.4 \%$, other inhalers: 87.7\%) (Table 3).

In most of the cases the inhaler handling was well integrated into the young patient's everyday life at visit $1(89.6 \%)$ and visit $2(93.3 \%)$ but the assessment of the inhaler usage by the physician was better when the children were treated with the $\mathrm{EH}$ (visit 1: $94.0 \%$, visit 2: $97.6 \%$ vs. other inhalers: visit 1: $85.0 \%$, visit $2: 88.9 \%$ ). In accordance to that, the physician indicated more difficulties in the inhaler handling when the 
Table 2. Demographic data of the patients

\begin{tabular}{|c|c|c|}
\hline & Children & $\begin{array}{l}\text { Adult/adoles- } \\
\text { cent patients }\end{array}$ \\
\hline No. of patients & 164 & 378 \\
\hline \multicolumn{3}{|l|}{ Gender } \\
\hline Male, n (\%) & $89(54.3)$ & $184(48.7)$ \\
\hline Female n (\%) & $71(43.3)$ & $189(50.0)$ \\
\hline Not reported n (\%) & $4(2.4)$ & $5(1.3)$ \\
\hline Mean age, years (SD) & $9,6(1,9)$ & $49.4(18.3)$ \\
\hline Age range, years & $3-12$ & $13-88$ \\
\hline \multicolumn{3}{|l|}{ Diagnosis } \\
\hline Asthma, n (\%) & $164(100.0)$ & $263(69.6)$ \\
\hline COPD, n (\%) & NR & $115(30.4)$ \\
\hline $\begin{array}{l}\text { Diagnosis known since, mon- } \\
\text { ths (SD) }\end{array}$ & $34.8(31.8)$ & $53.5(55.6)$ \\
\hline $\begin{array}{l}\text { Mean asthma severity }{ }^{*} \text {, grade } \\
\text { (SD) }\end{array}$ & $1.9(0.6)$ & $2.1(0.6)$ \\
\hline \multicolumn{3}{|l|}{ Mean COPD severity** } \\
\hline Stage A (mild), $n(\%)$ & NR & $7(6.1)$ \\
\hline Stage B (moderate), n (\%) & NR & $55(47.8)$ \\
\hline Stage C (severe), n (\%) & NR & $31(27.0)$ \\
\hline Stage D (very severe), $\mathrm{n}(\%)$ & NR & $16(13.9)$ \\
\hline Not reported, n (\%) & NR & $6(5.2)$ \\
\hline \multicolumn{3}{|l|}{ Comorbidities $^{* * *}$} \\
\hline neurological, n (\%) & $1(0.6)$ & $13(3.4)$ \\
\hline other, n (\%) & $30(18.3)$ & $129(34.1)$ \\
\hline none, $\mathrm{n}(\%)$ & $133(81.1)$ & $247(65.3)$ \\
\hline \multicolumn{3}{|l|}{ Smoking habits } \\
\hline Smoker & NR & $68(18.0)$ \\
\hline Former smoker, n (\%) & NR & $109(28.8)$ \\
\hline Non-smoker n (\%) & NR & $199(52.6)$ \\
\hline \multicolumn{3}{|l|}{ Used inhaler } \\
\hline $\mathrm{EH}, \mathrm{n}(\%)$ & $83(50.6)$ & $185(48.9)$ \\
\hline Other inhaler, n (\%) & $81(49.4)$ & $193(51.1)$ \\
\hline
\end{tabular}

patients used other inhalers (EH: visit 1: 4.8\%, visit $2: 3.6 \%$ vs. other inhalers: visit $1: 12.5 \%$, visit 2: 9.9\%). Similar differences could be found when the data of the patient's compliance were analyzed. In visit 1 , the physicians reported a very good or good compliance for $96.4 \%$ of the patients with an $\mathrm{EH}$ (other inhalers: 90.0\%). In visit 2, 98.8\% of the children with an EH showed a very good or good compliance (other inhalers: 87.7\%) (Fig. 1).
Table 3. Physician's assessment of the inhaler training in visit $\mathbf{0}$ for the children with asthmatic disease divided by used inhaler

\begin{tabular}{|c|c|c|}
\hline & EH n (\%) & Other inhaler $\mathbf{n}(\%)$ \\
\hline No. of patients & 83 & 81 \\
\hline \multicolumn{3}{|c|}{ Ease of teaching the correct use of the inhaler $(p<0.05)$} \\
\hline Very easy & $33(39.8)$ & $21(25.9)$ \\
\hline Fairly easy & $40(48.2)$ & $37(45.7)$ \\
\hline Somewhat easy & $10(12.0)$ & $14(17.3)$ \\
\hline Not very easy & 0 & $5(6.2)$ \\
\hline Hardly at all & 0 & $1(1.2)$ \\
\hline Not reported & 0 & $3(3.7)$ \\
\hline \multicolumn{3}{|c|}{ Was it necessary to repeat the training? $(p=N S)$} \\
\hline Yes & $33(39.8)$ & $38(46.9)$ \\
\hline No & $50(60.2)$ & $41(50.6)$ \\
\hline Not reported & 0 & $2(2.5)$ \\
\hline \multicolumn{3}{|c|}{ Was the instruction manual comprehensible? $(p=N S)$} \\
\hline Yes & $80(96.4)$ & 71 (87.7) \\
\hline No & $3(3.6)$ & $8(9.9)$ \\
\hline Not reported & 0 & $2(2.5)$ \\
\hline
\end{tabular}

Physician's assessment of inhaler training, inhaler usage and patient's compliance of the included adult/adolescent patients

Overall, for $81.6 \%$ of adult/adolescent patients with an EH but only for $64.8 \%$ of the patients with other inhalers the physician reported that it was very easy or fairly easy to teach the use of the respective inhaler. Interestingly, it was easier to teach patients with asthmatic disease $(80.2 \%)$ than COPD patients (56.5\%). Only one demonstration of the correct use of the inhaler was documented for $63.8 \%$ but in $52.3 \%$ of the patients with other inhaler. Patients with COPD needed more often a repetition of the training ( $56.5 \%$ vs. patients with asthma: $35.4 \%)$. Concerning the comprehensibility of the respective instruction manuals no differences could be found. The manuals were comprehensible in the vast majority of the cases (Table 4).

The inhaler handling in the patient's everyday life was in the most cases very good or good (EH: visit 1: 88.6\%, visit 2: 90.7\%; other inhalers: visit $1: 80.8 \%$, visit $2: 85.5 \%)$. There were no differences concerning the diagnosis. Overall, in five cases the physicians indicated a bad inhaler handling. All these patients were affected by asthma and used an EH. However, the occurrence of difficulties in the inhaler handling were less 


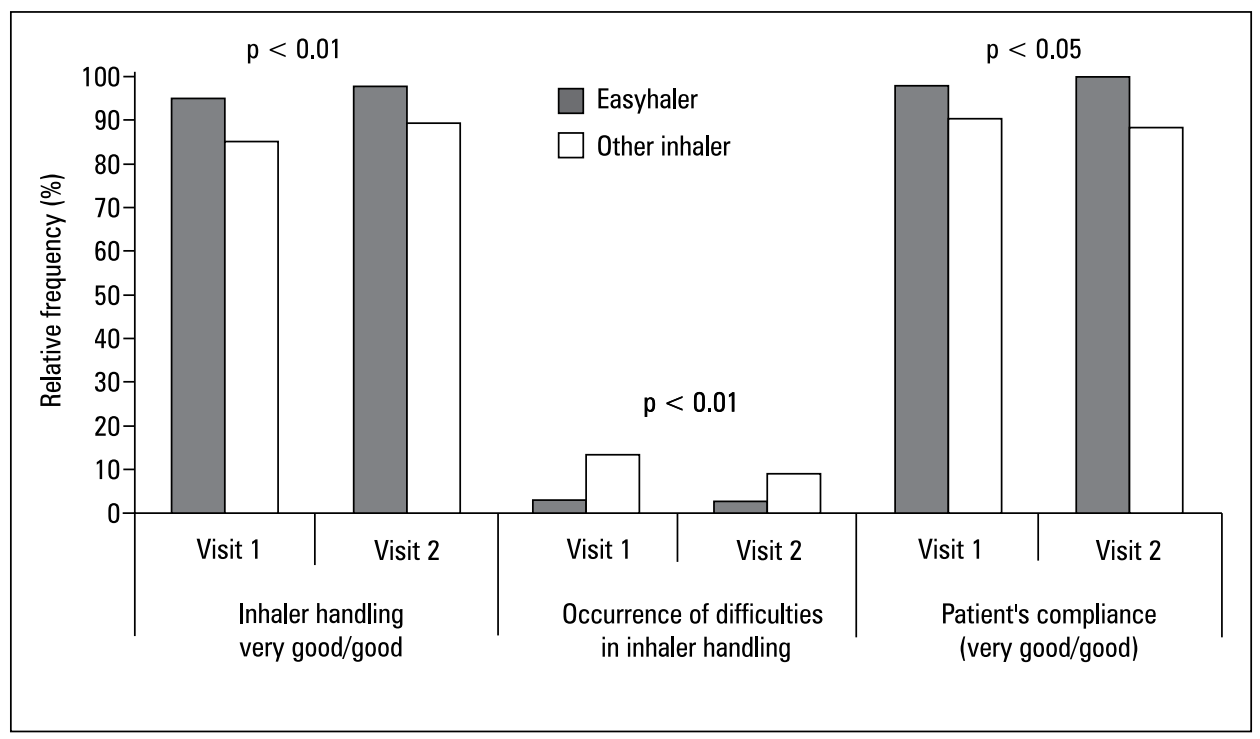

Figure 1. Physician's assessment of inhaler handling in patient's everyday life, occurrence of difficulties in inhaler handling and patient's compliance of included children in two visits in the study divided by used inhaler, integration of inhaler usage: relative frequencies of very good and good assessments by the physicians, patient's compliance: very good and good assessments by the physician; EH: N (visit 1): 83, N (visit 2): 83; other inhaler: $\mathrm{N}$ (visit 1): $81, \mathrm{~N}$ (visit 2): 80

p-values adjusted for visit

Table 4. Physician's assessment of the inhaler training at visit 0 for the adult patients divided by used inhaler and diagnosis

\begin{tabular}{|c|c|c|c|c|}
\hline & EH n (\%) & $\begin{array}{c}\text { Other inhaler } \\
\mathbf{n}(\%)\end{array}$ & Asthma n (\%) & COPD n (\%) \\
\hline No. of patients & 185 & 193 & 263 & 115 \\
\hline \multicolumn{5}{|c|}{ Ease of teaching the correct use of the inhaler } \\
\hline Very easy & $65(35.1)$ & $40(20.7)$ & $95(36.1)$ & $10(8.7)$ \\
\hline Fairly easy & $86(46.5)$ & $85(44.0)$ & $116(44.1)$ & $55(47.8)$ \\
\hline Somewhat easy & $24(13.0)$ & $59(30.6)$ & $45(17.1)$ & $38(33.0)$ \\
\hline Not very easy & $5(2.7)$ & $6(3.1)$ & $3(1.1)$ & $8(7.0)$ \\
\hline Hardly at all & $1(0.5)$ & 0 & $1(0.4)$ & 0 \\
\hline \multirow[t]{2}{*}{ Not reported } & $4(2.2)$ & $3(1.6)$ & $3(1.1)$ & $4(3.5)$ \\
\hline & \multicolumn{2}{|c|}{$(p<0.01)^{*}$} & \multicolumn{2}{|c|}{$(p<0.01)^{* *}$} \\
\hline \multicolumn{5}{|c|}{ Was it necessary to repeat the training? } \\
\hline Yes & $66(35.7)$ & $92(47.7)$ & $93(35.4)$ & $65(56.5)$ \\
\hline No & $118(63.8)$ & $101(52.3)$ & $170(64.6)$ & $49(42.6)$ \\
\hline \multirow[t]{2}{*}{ Not reported } & $1(0.5)$ & 0 & 0 & $1(0.9)$ \\
\hline & \multicolumn{2}{|c|}{$(p<0.05)^{*}$} & \multicolumn{2}{|c|}{$(p<0.01)^{* *}$} \\
\hline
\end{tabular}

Was the instruction manual comprehensible?

\begin{tabular}{lcccc}
\hline Yes & $178(96.2)$ & $177(91.7)$ & $247(93.9)$ & $108(93.9)$ \\
No & $6(3.2)$ & $16(8.3)$ & $15(5.7)$ & $7(6.1)$ \\
Not reported & $1(0.5)$ & 0 & $1(0.4)$ & 0 \\
\hline \multicolumn{3}{c}{$(p<0.05)^{*}$} & & $(p=N S)^{* *}$ \\
\hline
\end{tabular}

COPD - chronic obstructive pulmonary disease

*between $\mathrm{EH}$ and other inhaler

**between Asthma and COPD 


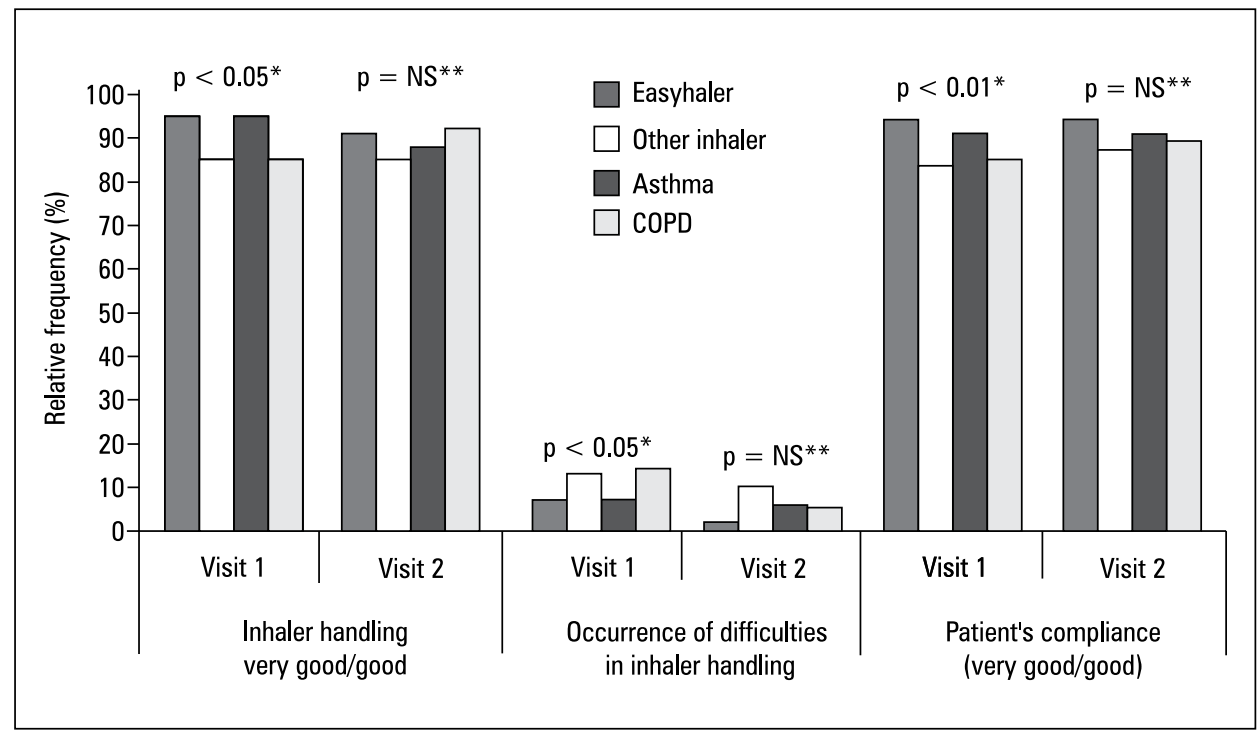

Figure 2. Physician's assessment of inhaler handling in patient's everyday life, occurrence of difficulties in inhaler handling and patient's compliance of included adult patients in two visits in the study divided by used inhaler and diagnosis, integration of inhaler usage: relative frequencies of very good and good assessments by the physicians, patient's compliance: very good and good assessments by the physician; EH: N (visit 1): 184, N (visit 2): 183; other inhaler: N (visit 1): 191, N (visit 2): 193; asthma: N (visit 1): 263, N (visit 2): 262, COPD: N (visit 1): $114, N$ (visit 2): 114

COPD - chronic obstructive pulmonary disease

*between $\mathrm{EH}$ and other inhaler

**between asthma and COPD

frequently documented when patients used an EH (visit 1: $4.9 \%$, visit $2: 1.1 \%$ vs. other inhalers: visit 1: $13.0 \%$, visit $2: 9.3 \%)$. Interestingly, at visit 1 there were clearly more difficulties in the inhaler handling at the group of COPD patients (14.0\% vs. asthma: $6.8 \%$ ), but these differences disappeared at visit 2 (COPD: $4.4 \%$ vs. asthma: $5.7 \%)$. Similar to the data of the children, the compliance of the adult/adolescent patients with an EH was better than the compliance of patients with other inhalation devices (Fig. 2).

\section{Assessment of inhaler usage and general assessment of the inhaler by the children and their parents or legal guardians}

In total, the children used their respective inhaler in the mean two times per day. This inhalation frequency did not change during the observation period. In addition, there were no differences regarding the used inhalers (visit 0 : $2.2 \pm 0.9$ inhalations per day, visit $1: 2.1 \pm 0.8$ inhalations per day, visit 2: $2.3 \pm 1.1$ inhalations per day).

The assessment of the inhaler usage by the children and their parents or legal guardian were very similar. In all visits, the Inhaler Usage Score for $\mathrm{EH}$ was better than for the other inhalation devices. The best Inhaler Usage Score was do- cumented for $\mathrm{EH}$ at visit 2 (children: $1.6 \pm 0.5$, parents/legal guardian: $1.7 \pm 0.5$ ). For the other inhalation devices the children documented an Inhaler Usage Score of $2.0 \pm 0.9$ at visit 2 (parents/legal guardian: $2.1 \pm 0.8$ ) (Fig. 3). However, the combined Inhaler Usage Score showed no significant differences between the assessments of $\mathrm{EH}$ and of the other inhalation devices (Table 5).

In accordance to the Inhaler Usage Score, the general assessment of the $\mathrm{EH}$ was better than the assessment for other inhalers. At visit 2 the children indicated $1.6 \pm 0.7$ according to school marks and their parents or legal guardians reported $1.6 \pm 0.6$. The general assessment by the children for other inhalation devices was $1.9 \pm 0.9$ at visit 2 according to school marks (parents/legal guardian visit 2: $2.1 \pm 0.9$ ) (Fig. 4).

Inconvenient features were documented more often when the children used other inhalers. At visit $0,28.8 \%$ of the young patients with other inhalation devices reported inconvenient features, at visit 1 in $22.2 \%$ and at visit $225.0 \%$. In contrary, only $16.9 \%$ of the patients with an $\mathrm{EH}$ noticed inconvenient features at visit $0,10.8 \%$ in visit 1 and $8.4 \%$ at visit 2 . The most frequently documented inconvenient feature was bad taste.

In order to evaluate the consistency of the received data, the Cronbachs alpha coefficient 


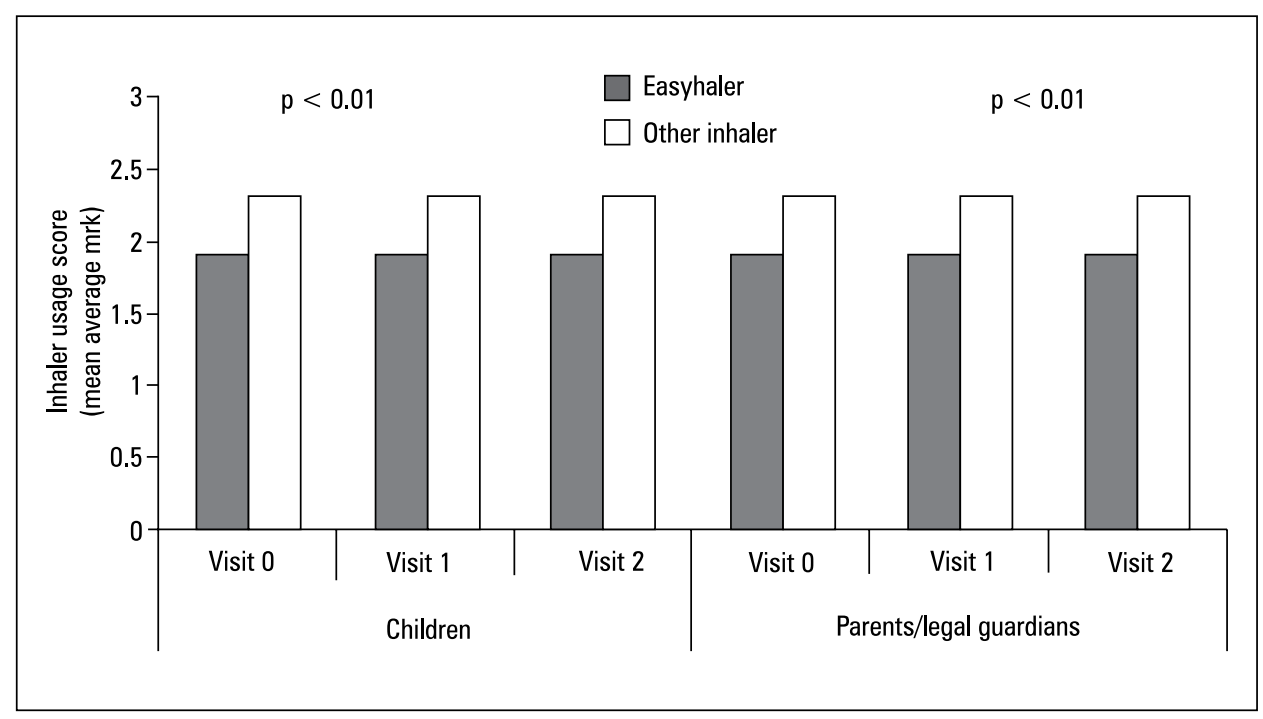

Figure 3. Inhaler usage score documented by the children and their parents/legal guardians in visit 0 , visit 1 and visit 2 divided by used inhaler, inhaler usage score as mean average mark: $1=$ very good to $6=$ insufficient, the score was calculated by summarizing the documented school marks documented for the five questionnaire items concerning inhaler usage (inhaler training, inhaler handling, daily activities, breathing in and stability) and division by 5 . children: $\mathrm{EH}: \mathrm{N}=83$, other inhaler: $\mathrm{N}=79$; parents/legal guardians: $\mathrm{EH}: \mathrm{N}=83$, other inhaler: $\mathrm{N}=78$ p-values adjusted for visit

Table 5. Combined Inhaler Usage Score and results of Student's t-tests (combined Inhaler Usage Score EH vs. other inhalers, significance level, $p=0.05$ ); Children: $N$ (visit 0): 163, $N$ (visit 1): 164, $N$ (visit 2): 163; Parents/ legal guardian: $\mathbf{N}$ (visit 0): 162, N (visit 1): 164, N (visit 2): 163; Adult/adolescent patients: $\mathbf{N}$ (visit 0): 378, $\mathbf{N}$ (visit 1): 376 , $\mathbf{N}$ (visit 2): 375, Adult/adolescent patients with asthma and children: $\mathbf{N}$ (visit 0): 426, $\mathbf{N}$ (visit 1): 427, $\mathbf{N}$ (visit 2): 425, Adult patients with COPD: N (visit 0): 115, N (visit 1): 113, N (visit 2): 113, Adult/adolescent patients and children: N (visit 0): $541, \mathbf{N}$ (visit 1): 540, N (visit 2): 538

\begin{tabular}{|c|c|c|c|c|c|c|c|c|c|}
\hline & \multicolumn{3}{|c|}{ Visit 0} & \multicolumn{3}{|c|}{ Visit 1} & \multicolumn{3}{|c|}{ Visit 2} \\
\hline & EH & 이 & $\mathbf{p}$ & EH & 이 & $\mathbf{p}$ & EH & 이 & $\mathbf{p}$ \\
\hline Children & $1.6 \pm 0.4$ & $1.7 \pm 0.4$ & 0.1941 & $1.6 \pm 0.4$ & $1.6 \pm 0.4$ & 0.2256 & $1.6 \pm 0.4$ & $1.6 \pm 0.4$ & 0.3794 \\
\hline Parent/legal guardian & $1.7 \pm 0.4$ & $1.8 \pm 0.4$ & 0.3489 & $1.7 \pm 0.4$ & $1.7 \pm 0.4$ & 0.9247 & $1.6 \pm 0.4$ & $1.7 \pm 0.4$ & 0.2038 \\
\hline $\begin{array}{l}\text { Adult/adolescent } \\
\text { patients }\end{array}$ & $1.7 \pm 0.4$ & $1.8 \pm 0.4$ & 0.0153 & $1.6 \pm 0.4$ & $1.7 \pm 0.4$ & 0.0004 & $1.5 \pm 0.4$ & $1.7 \pm 0.4$ & $<.0001$ \\
\hline $\begin{array}{l}\text { Adult/adolescent } \\
\text { patients with asthma } \\
\text { and children }\end{array}$ & $1.6 \pm 0.4$ & $1.7 \pm 0.4$ & 0.0103 & $1.5 \pm 0.4$ & $1.7 \pm 0.4$ & 0.0007 & $1.5 \pm 0.4$ & $1.6 \pm 0.4$ & 0.0010 \\
\hline $\begin{array}{l}\text { Adult patients with } \\
\text { COPD }\end{array}$ & $1.8 \pm 0.3$ & $1.9 \pm 0.3$ & 0.3810 & $1.7 \pm 0.4$ & $1.8 \pm 0.4$ & 0.3051 & $1.6 \pm 0.4$ & $1.8 \pm 0.4$ & 0.0653 \\
\hline $\begin{array}{l}\text { Adult/adolescent } \\
\text { patients and children }\end{array}$ & $1.7 \pm 0.4$ & $1.8 \pm 0.4$ & 0.0054 & $1.6 \pm 0.4$ & $1.7 \pm 0.4$ & 0.0003 & $1.5 \pm 0.4$ & $1.7 \pm 0.4$ & 0.0001 \\
\hline
\end{tabular}

COPD — chronic obstructive pulmonary disease, $0 \mathrm{O}$ — other inhaler

was calculated. The calculation was based on 463 questionnaires filled by the children and 467 questionnaires filled by the parents or legal guardians at all three visits. The internal consistency of the questionnaires was excellent. The received standardized value of alpha was 0.93 for both, the children's questionnaires and the questionnaires for the parents/legal guardians. The linear correlation between the inhaler usage score and the general assessment was 0.77 for the results of the questionnaires documented by the children and 0.80 for the data from the questionnaires for parents/legal guardians. In both cases, there was a large linear association between Inhaler Usage Score and general assessment of the respective inhalers (Table 6). 


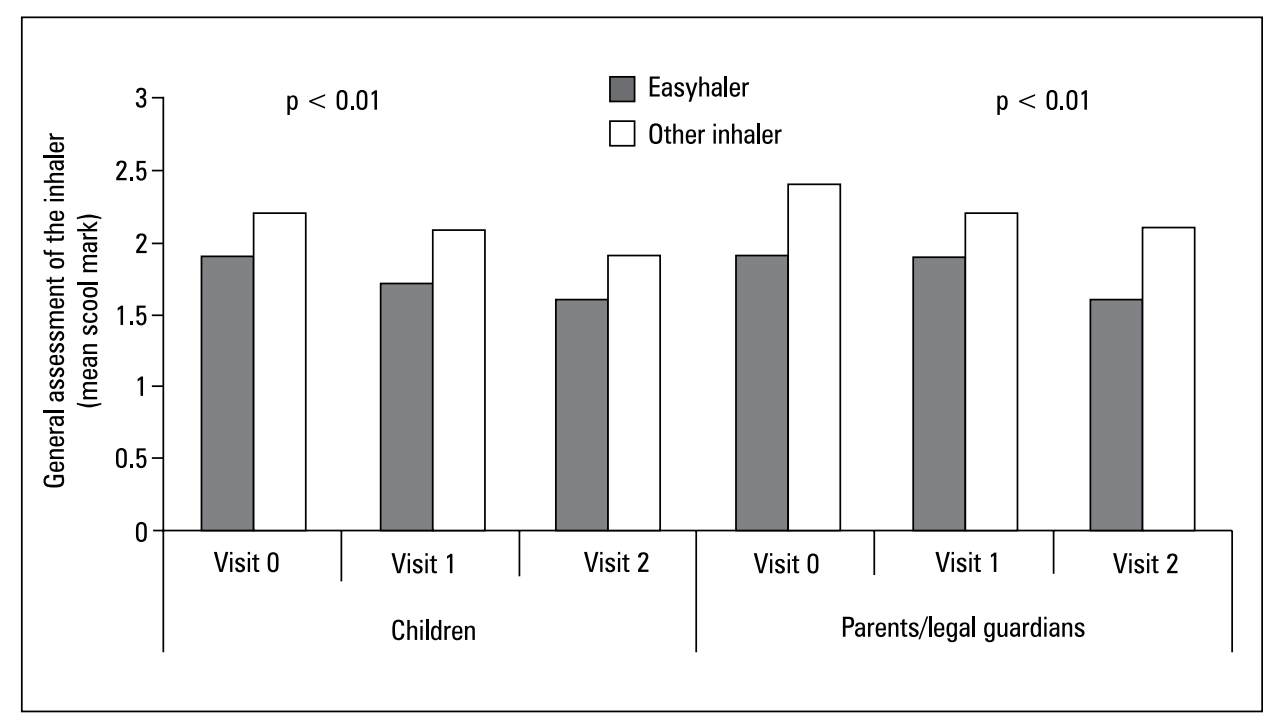

Figure 4. General assessment of the inhaler documented by the children and their parents/legal guardians in visit 0 , visit 1 and visit 2 divided by used inhaler, mean school mark: $1=$ very good to $6=$ insufficient, children: $\mathrm{EH}: \mathrm{N}=83$, other inhaler: $\mathrm{N}=79$; parents/legal guardians: EH: $\mathrm{N}=$ 83, other inhaler: $\mathrm{N}=78$

p-values adjusted for visit

Table 6. Pearson Correlation Coefficient $r$ (correlation between Inhaler Usage Score and general assessment of the inhaler) and Cronbachs alpha (internal consistency of the answers in the questionnaires)

\begin{tabular}{lcc}
\hline & $\begin{array}{c}\text { Children/parents } \\
\text { or legal guardian }\end{array}$ & $\begin{array}{c}\text { Adult/ } \\
\text { adolescent } \\
\text { patients }\end{array}$ \\
\hline \multicolumn{3}{c}{ Pearson Correlation Coefficient $\mathbf{r}$} \\
\hline Number of questionnaires & $463 / 462$ & 1066 \\
r value & $0.77 / 0.80$ & 0.85 \\
\hline \multicolumn{3}{c}{ Cronbachs alpha } \\
\hline Number of questionnaires & $465 / 467$ & 1076 \\
alpha value (standardized) & $0.93 / 0.92$ & 0.95 \\
\hline
\end{tabular}

\section{Assessment of inhaler usage and general assessment of the inhaler by the adult/ /adolescent patients}

The adult/adolescent patients used their respective inhalers in the mean also two times per day. This inhalation frequency did not change during the study (visit 0: $2.1 \pm 0.7$ inhalations per day, visit 1: $2.2 \pm 1.0$ inhalations per day, visit 2: $2.2 \pm 1.0$ inhalations per day). In addition, differences regarding used inhaler and diagnosis could not be found (visit 2: $\mathrm{EH} /$ asthma: $2.3 \pm 1.2$, EH/COPD: $2.2 \pm 0.5$, other inhaler/asthma: $2.2 \pm 1.0$, other inhaler/COPD: $2.0 \pm 0.4)$.

The patients that used an $\mathrm{EH}$ assessed the usage of the inhaler better than the patients with other inhalation devices but there were differences in the score in connection with the diagnosis. The best score was documented in visit 2 by patients with asthma that used an EH (1.5 \pm 0.6$)$. COPD patients with an EH assessed the inhaler at beginning of the study not that good, but the score improved during the observation period. In visit 0 , there was a mean Inhaler Usage Score of $2.4 \pm 0.8$ and in visit 2 it was $1.7 \pm 0.5$. The same could be found for the patients that were treated with other inhalers. Patients with asthma (visit 2: $1.9 \pm 0.7)$ assessed their respective inhaler better than patients with COPD (visit 2: $2.1 \pm 0.7$ ) (Fig. 5). Overall, the analysis of the combined inhaler usage score of the patients with an $\mathrm{EH}$ compared to those with other inhalers showed significantly better assessments for $\mathrm{EH}$, but that was dependent on the diagnosis. The combined Inhaler Usage Scores of COPD patients with EH and other inhalers showed no significant differences (Table 5). The results were confirmed by the general assessment of the inhalers. The best assessments were documented at visit 2 by the patients that were affected by asthma and used an EH (1.6 \pm 0.7 vs. other inhalers: $1.9 \pm 0.8)$. Patients with COPD and EH documented a mean school mark of $1.7 \pm 0.6$ at visit 2 (vs. other inhalers: $2.2 \pm 0.8$ ) (Fig. 6). 


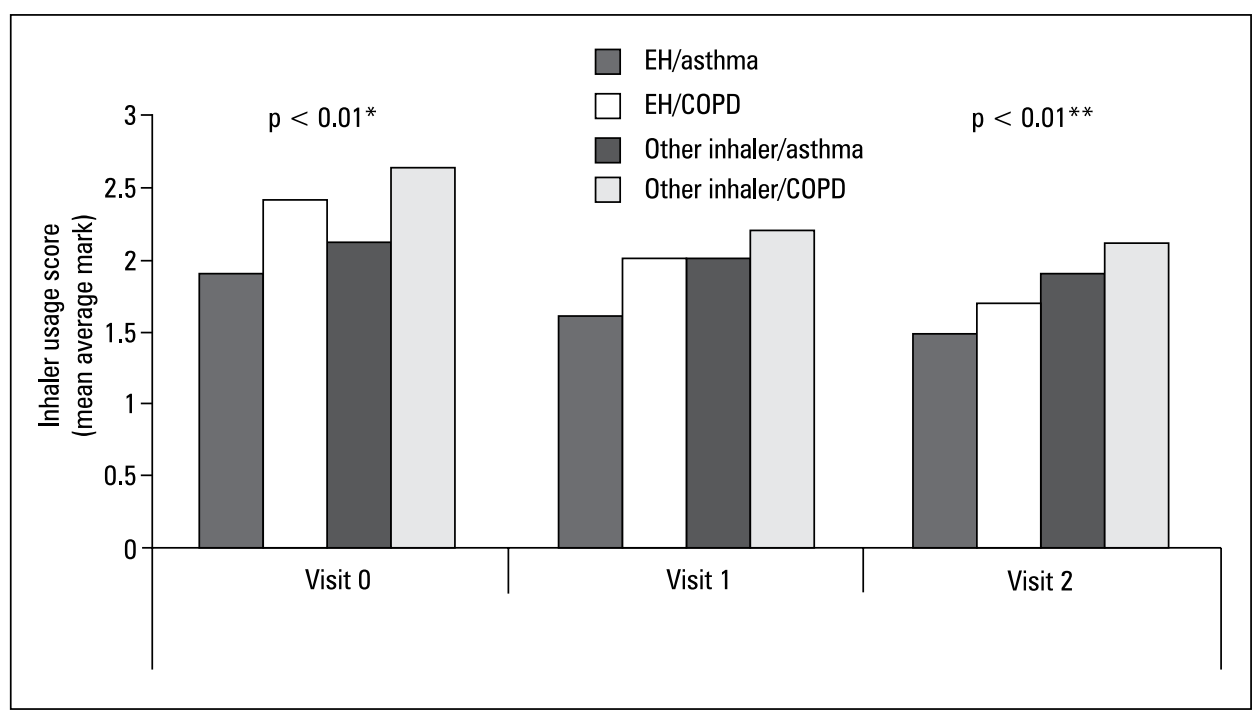

Figure 5. Inhaler Usage Score documented by the adult/adolescent patients in visit 0, visit 1 and visit 2 divided by used inhaler and diagnosis, inhaler usage score as mean average mark: $1=$ very good to $6=$ insufficient, the score was calculated by summarizing the documented school marks for the seven questionnaire items concerning inhaler usage (inhaler training, preparation for utilization, inhaler handling, success of inhalation, daily activities, cleaning of the inhaler, size and weight) and division by 7. EH/asthma: $N=129, E H / C O P D: N=53$; other inhaler/asthma: $N=133$, other inhaler/COPD: $\mathrm{N}=59$

COPD — chronic obstructive pulmonary disease

*adjusted for visit and test between $\mathrm{EH} /$ asthma and other inhaler/asthma

**adjusted for visit and test between EH/COPD and other inhaler/COPD

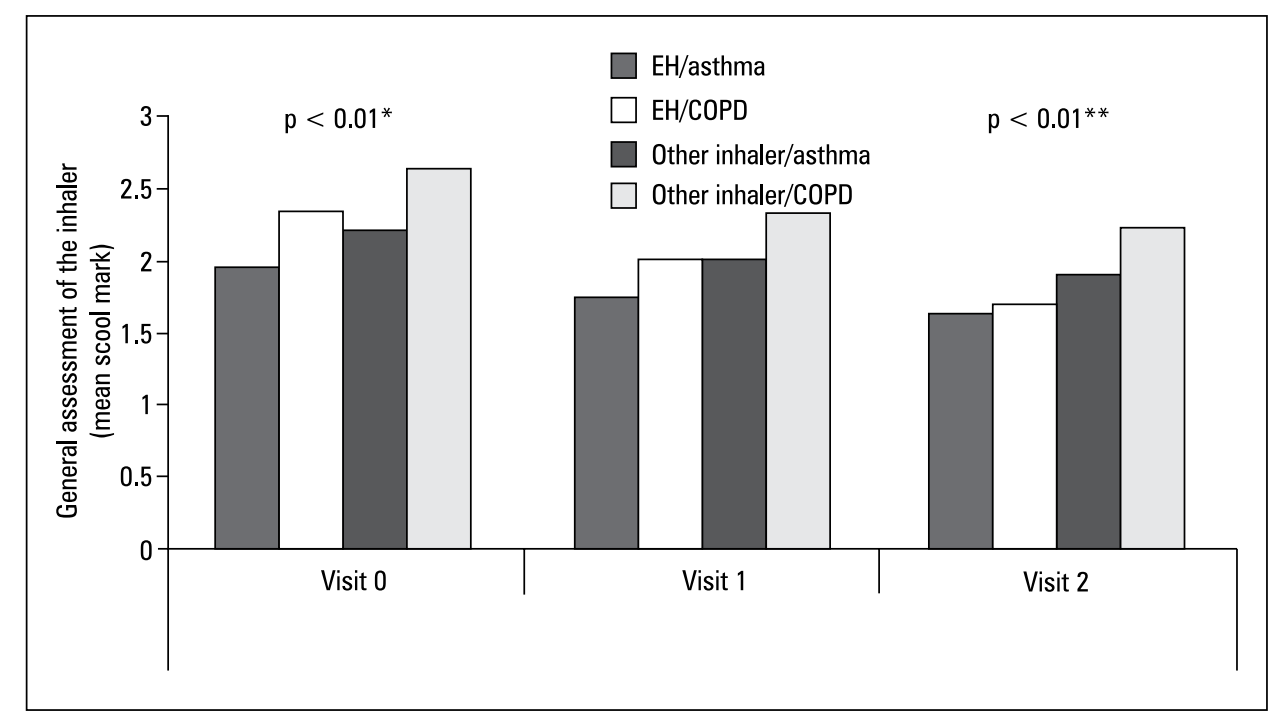

Figure 6. General assessment of the inhaler documented by the adult/adolescent patients in visit 0 , visit 1 and visit 2 divided by used inhaler and diagnosis, mean school mark: $1=$ very good to $6=$ insufficient, EH/asthma: $N=129$, EH/COPD: $N=53$; other inhaler/asthma: $N=133$, other inhaler/COPD: $\mathrm{N}=59$

COPD - chronic obstructive pulmonary disease

*adjusted for visit and test between EH/asthma and other inhaler/asthma

**adjusted for visit and test between EH/COPD and other inhaler/COPD 
The most inconvenient features were documented by the adult patients that used other inhalers (visit 0: $29.3 \%$ of patients with asthma and $30.0 \%$ of COPD patients, visit $1,24.1 \%$ of patients with asthma and $35.0 \%$ of patients with COPD, visit 2 in $24.1 \%$ of the patients with asthma and in $28.8 \%$ of the patients with COPD). The proportion of patients that indicated inconvenient features of an EH was clearly lower (visit 0: 17.7\% of patients with asthma and $9.1 \%$ of patients with COPD, visit $111.5 \%$ of patients with asthma and $9.4 \%$ of patients with COPD, visit 2: $10.9 \%$ of patients with asthma and $5.6 \%$ of patients with COPD). The most frequently documented features were bad taste and the occurrence of hoarseness.

The calculation of the internal consistency by using Cronbachs alpha was based on 1,129 filled questionnaires from adult/adolescent patients during the observation period. The received standardized value of alpha was 0,96 . Similar to the data from the children and parents/legal guardian, the internal consistency of the data from the adult patient's questionnaire was excellent. That was confirmed by the Pearson correlation coefficient $r$, which was approximately 0.85 . Thus, there was a large correlation between the Inhaler Usage Score and the general assessment of the inhalers (Table 6).

\section{Adverse events}

During the observation period, adverse events were documented for three patients $(0.5 \%)$. In two cases there were more information available. The first patient was a child and affected by pharyngitis and snoring. The second patient was an adult COPD patient. In this case, the described events were irritant cough, hoarseness and "vibration of the vocal cords". Both patients used an EH and in both cases the medication was permanently discontinued.

\section{Discussion}

Asthma and COPD are common diseases of the airways and lungs that have a major impact on the health of the population. The mainstay of treatment is by inhalation of medication to the site of the disease process [14]. Proper inhaler technique is crucial for effective management of asthma and COPD. Incorrect usage of inhalers may result in diminished therapeutic effect, poor control of symptoms and thereby insufficient disease management [6, 7]. Several authors have compared inhaler competences, inhaler usage, and patient satisfaction with different inhalers [5, 7, 9-11].
Meta-analyses indicate that when patients can apply the correct inhalation technique, all inhalers can achieve the same therapeutic effects, although different metered or delivered doses are required [16, 17]. The relative effectiveness of delivery methods does not provide a clear basis for selecting one device over another. Patient's preferences also play an important role when prescribing an inhaler [18]. The literature highlights that dose emission from $\mathrm{EH}$ is fairly consistent irrespective of the inhalation technique used by patients of all age groups. Clinical studies have shown equivalence of this device to those frequently prescribed and that it is preferred by many patients $[10,11,19,20]$. The limitation of these studies was that most of the included patients with airway diseases have used inhaler devices previously and had a good idea about inhalation manoeuvres in general. In this study, inhaler usage and patient satisfaction was investigated with children and adult/adolescent patients with asthma or COPD that had no or only few experiences with inhalation devices. Altogether, more than 500 patients were included and they represent a wide range of age (3-88 years) and different educational background. The possible tendency for people with higher graduation to start certain therapies as well as participation in various studies may account for the noticeably high percentage of patients with higher graduations enrolled in this study. On the other hand, physicians may have been prone to ask patients with higher education to participate in such studies because they supposed that those patients would show a better compliance. There were no limitations concerning the other inhalation devices.

Inhaler training was easier with $\mathrm{EH}$ in all patient groups. A second or third instruction of the usage of EH was necessary only for $39.8 \%$ of the children, $35.1 \%$ of the adult/adolescent patients, whereas $46.9 \%$ of the children and $47.7 \%$ of the adult/adolescent patients with other inhalers needed a repetition of the inhaler training. Interestingly, for more than $85.0 \%$ of the patients in all patient groups the physicians reported that the instruction manual was comprehensible. These findings are consistent with the suggestion that the quality of initial instruction is of paramount importance and that written instruction alone is inadequate in teaching correct inhalation technique. In addition, it is necessary to check the results of the training at regular intervals. Verbal instruction and technique assessment and reassessment are essential for patients to achieve proper technique, especially at therapy start [21, 22]. 
This is consistent with the results of our study. Assessment of the inhaler usage by the physician was conducted 2 weeks and 8 weeks after the initial training. The usability of the inhaler in the patient's life increased during this time whereas the occurrence of difficulties in inhaler handling decreased for all used inhalation devices. In this context, also the compliance of the patients slightly increased during the observation period in all patient groups except the children with other inhalers. However, inhaler usability as well as patient's compliance were assessed better by the investigators when the patients used an EH. The same could be found in the patient's questionnaires. Overall, the assessment of inhaler usage of $\mathrm{EH}$ was significantly better than the evaluation of other inhalation devices. No significant differences could be found for the Inhaler Usage Score documented by the children as well as in the COPD patient group, although the scores were similar to the scores documented by the adult patients in total and the adult asthma patients. It can be suggested that this was a result of the smaller number of participating children and COPD patients. The general assessment of $\mathrm{EH}$ was also clearly better. In addition, there were less inconvenient features of $\mathrm{EH}$ than of other inhalers with the same inhalation frequency. Nevertheless, verbal support of the patients at visit 1 and visit 2 as well as daily practice led to an improvement of the assessment during the study in general. Similar to the decreased number of patients with difficulties in inhaler handling at visit 2 in comparison with visit 0 , the Inhaler Usage Score and thereby the general assessment of all used inhalers increased.

One limitation of this study was surely the lack of clinical parameters to evaluate the effectiveness of treatment. But it has been suggested that the ease of use of an inhaler device may correlate with inhaler competence and thereby with adherence to treatment [7]. A device that is easy to teach to use correctly might also be better suited for children and elderly patients who may find learning new skills difficult [23]. In the present study, there were no clear differences in the assessment of the inhaler by the children in comparison to the adult patients. The physicians reported for $88.0 \%$ of the children that used an $\mathrm{EH}$ and $71.6 \%$ of the children with other inhalation devices that it was very easy or fairly easy to teach the correct use of the inhaler, in the case of the adult patients the same was documented for $81.6 \%$ with an $\mathrm{EH}$ and $64.8 \%$ with other inhalers. These results actually suggest that it was easier to teach children the correct use of the inhalers.

One noticeable finding was also the differences in physician's and patient's assessment of inhaler usage between patients with asthma and those who were affected by COPD. The physicians reported very easy or fairly easy inhaler training for $80.2 \%$ of the patients with asthma and for only $56.5 \%$ of the patients with COPD. $56.5 \%$ of the patients with COPD needed a repetition of the inhaler training but only $35.4 \%$ of the patients with asthma. Inhaler Usage Score as well as general assessment of the inhaler by the COPD patients were worse than the evaluations documented by asthma patients irrespective of the used inhaler. There are indications that patients with COPD are unable to use a pressurized metered dose inhaler (pMDI) correctly. Common errors include inadequate coordination in inspiration and actuation and inability to achieve a high enough inspiratory flow rate. One study with Accuhalers and Turbuhalers also showed that patients with severe COPD were less likely to achieve a high enough inspiratory rate to activate the inhaler, even after instruction [24]. Other authors demonstrated that asthmatic patients had a lower risk of critical errors than COPD patients, but this relationship disappeared after adjustment of device, age and level of instruction [7]. It was also highlighted that the better results in asthmatic patients did not match the results observed in COPD patients despite proper instructions on inhalation technique in both patient groups [25]. In addition to this, both age and COPD duration are associated with cognitive decline. Cognitive disorders, especially memory problems, can also lead to non-adherence in patients with COPD [26].

The present study was primarily conducted to validate a questionnaire that can be used for assessing a successful inhalation technique and the compliance of the patients in daily practice. Analyses of correlation and internal consistency showed that all patient groups understood and used the questionnaires correctly and it was suitable for children as well as elderly patients. The items in the questionnaire reflected the factors that play an important role for the choice of the patients for one or another inhalation device, such as handling, cleaning, size, weight, ease and success of inhalation.

\section{Conclusion}

The results of this study are similar to those found by other authors that compared inhaler competence and patient satisfaction with $\mathrm{EH}$ 
and other inhalers. Keeping in mind the inherent variability among patients, it may be preferable that inhalers should be matched to the patient. It is also recommended that only one type of inhaler should be prescribed. According to the patient's preferences, the best inhaler should be portable, easy to use and demonstrate dosing accuracy and consistency over a wide range of inspiratory flows. The results of this study show that investigators found $\mathrm{EH}$ easy to teach and the patients found it easy to use and their satisfaction with the device was high in comparison to other inhalation devices. Thus, EH can be matched to many patients already at the therapy start. In addition, the high consistency of the received data and large association of the assessment of the inhaler usage and the general assessment of the inhaler indicate that the used questionnaires were appropriate tools to examine usage and usability of inhaler devices for patients of all age groups.

\section{Conflicts of interests}

K.W. and J.O. are employees of INPADS $\mathrm{GmbH}$. The present study was performed in INPADS GmbH with commission by Orion Corporation (Orion Pharma). P.R., P.H. and Y.H. are employees of Orion Pharma.

\section{Acknowledgements}

The authors would like to thank the participating physicians in Germany and Poland for their valuable contribution to the study.

\section{References:}

1. Global Initiative for Asthma (GINA). Global Strategy for Asthma Management and Prevention 2014. Available from: www. ginasthma.org; 1.05.2015.

2. Global Initiative for Chronic Obstructive Lung Disease (GOLD). Global strategy for the diagnosis, management, and prevention of chronic obstructive pulmonary disease 2015. Available from: www. goldcopd.org; 1.05.2015.

3. Murray CJL, Lopez AD. Alternative projection of mortality and disability by cause 1990-2020: Global Burden of Disease Study. Lancet 1997; 349: 1498-1504.

4. Laube BL, Jannssens HM, de Jongh FHC et al. What the pulmonary specialist should know about the new inhalation therapies. Eur Respir J 2011; 37: 1308-1031 doi: 10.1183/09031936.00166410.

5. van der Palen J, Klein JJ, van Herwaarden CLA, Zielhuis GA, Seydel ER. Multiple inhalers confuse asthma patients. Eur Respir J 1999;14: 1034-1037.

6. Lavorini F, Magnan A, Dubus JC et al. Effect of incorrect use of dry powder inhalers on management of patients with asthma and COPD. Respir Med 2008; 102: 593-604.
7. Melani AS, Bonavia M, Cilenti V et al. Inhaler mishandling remains common in real life and is associated with reduced disease control. Respir Med 2011; 105: 930-938. doi: 10.1016/j. rmed.2011.01.005.

8. Malmberg LP, Everard ML, Haikarainen J, Lahelma S. Evaluation of in vitro and in vivo flow rate dependency of budesonide/formoterol Easyhaler $\left({ }^{\circledast}\right)$. J Aerosol Med Pulm Drug Deliv 2014; 27: 329-340. doi: 10.1089/jamp.2013.1099.

9. Chrystyn H. Closer to an "ideal inhaler" with the Easyhaler ${ }^{\oplus}$. Clin Drug Investig 2006; 26: 175-183.

10. Ahonen A, Leinonen M, Rank-Pesonen M. Patient satisfaction with Easyhaler compared with other inhalation systems in the treatment of asthma: a meta-analysis. Cur Ther Res 2000; 61: 61-73.

11. Giner J, Torrejon M, Ramos A et al. Patient preferences in the choice of dry powder inhalers. Arch Bronconeumol 2004; 40: $106-109$.

12. Rönmark E, Jögi R, Lindqvist A et al. Correct use of three powder inhalers: comparison between Diskus, Turbohaler, and Easyhaler ${ }^{\circledast}$. J Asthma 2005; 42: 173-178.

13. Galffy G, Mezei G, Nemeth G et al. Inhaler competence and patient satisfaction with Easyhaler ${ }^{\oplus}$ : results of two real-life multicentre studies in asthma and COPD. Drugs R D 2013; 13 : 215-222 doi: 10.1007/s40268-013-0027-3.

14. National Asthma Education and Prevention Program, Expert Panel Report 2. Guidelines for the diagnosis and management of asthma. Washington DC: Dept. of Health and Human Services 1997; NIH Publication No. 97-4015.

15. Colice CL. Categorizing asthma severity: An overview of national guidelines. Clin Med Res. 2004; 2: 155-163.

16. Brocklebank D, Ram F, Wright J et al. Comparison of the effectiveness of inhaler devices in asthma and chronic obstructive airway disease: a systematic review of the literature. Health Technol Assess 2001; 5: 1-149.

17. Dolovich MB, Ahrens RC, Hess DR et al. Device selection and outcomes of aerosol therapy: evidence-based guidelines. American College of Chest Physicians/American College of Asthma, Allergy, and Immunology. Chest 2005; 127: $335-371$.

18. Lenney J, Innes JA, Crompton GK. Inappropriate inhaler use: assessment of use and patients preference of seven inhalation devices. Resp Med 2000; 94: 496-500.

19. Schweisfurth H, Malinen A, Koskela T, Toivanen P, Ranki-Pesonen M. Comparison of two budesonide powder inhalers, Easyhaler $^{\oplus}$ and Turbuhaler ${ }^{\oplus}$, in steroid-naive asthmatic children. Respir Med 2002; 96: 599-606.

20. Vanto T, Hämäläinen KM, Vahteristo M, Wille S, Nja F, Hyldebrandt N. Comparison of two budesonide dry powder inhalers in the treatment of asthma in children. J Aerosol Med 2004; 17: $15-24$

21. Pedersen S, Frost L, Arnfred T. Errors in inhalation technique and efficiency in inhaler use in asthmatic children. Allergy 1986; 41: 118-124.

22. Nimmo CJR, Chen DNM, Martinusen SM, Ustad TL, Ostrow DN. Assessment of patient acceptance and inhalation technique of a pressurized aerosol inhaler and two breath-actuated devices. Ann. Pharmacother 1993; 27: 922-927.

23. Crompton GK, Barnes PJ, Broeders $\mathrm{M}$ et al. The need to improve inhalation technique in Europe: A report from the aerosol drug management improvement team. Resp Med 2006; 100: 1479-1494.

24. Broeders MEAC, Molema J, Hop WCJ, Folgering HTM. Inhalation profiles in asthmatic and COPD patients: reproducibility and effect of instruction. J Aerosol Med 2003; 16: 131-141.

25. Restrepo RD, Alvarez MT, Wittnebel LD. et al. Medication adherence issues in patients treated for COPD International Journal of COPD 2008; 3: 371-384.

26. Bourbeau J, Bartlett SJ. Patient adherence in COPD Thorax 2008; 63: 831-838 doi: 10.1136/thx.2007.086041. 